\title{
Psicoterapia dialógica como cenário social favorecedor de desenvolvimento subjetivo infantil
}

\author{
Camila Cardoso de Moraes Montü \\ Valéria Deusdará Mori* \\ Júlia Sursis Nobre Ferro Bucher-Maluschkee
}

\begin{abstract}
Resumo
A presente pesquisa tem o objetivo central de compreender como a psicoterapia dialógica, na perspectiva da Teoria da Subjetividade, pode mobilizar novos processos simbólico-emocionais que favoreçam o desenvolvimento subjetivo infantil. O desenvolvimento subjetivo é um fenômeno complexo e singular, configurado subjetivamente ao longo do tempo, a partir dos diversos sentidos subjetivos que emergem e vão tomando forma na relação com o outro, marcado pela capacidade de o indivíduo gerar novas produções subjetivas que o levem a abrir caminhos e possibilidades de vivenciar suas experiências. Foi realizado um estudo de caso que possibilitou compreender as configurações subjetivas da criança em psicoterapia, gerando inteligibilidade acerca das mudanças e novas produções subjetivas ao longo desse processo. A Epistemologia Qualitativa serviu de base à Teoria da Subjetividade de González Rey, em uma perspectiva cultural-histórica, norteando este trabalho na produção de conhecimento que ocorreu de forma construtivo-interpretativa. A análise interpretativa do caso permitiu evidenciar o caráter subjetivo das relações construídas no espaço psicoterapêutico e a possibilidade de desenvolvimento subjetivo da criança. Palavras-chave: subjetividade; psicoterapia; desenvolvimento infantil; desenvolvimento subjetivo.
\end{abstract}

\section{Dialogic psychotherapy as a social scenario that favors child subjective development}

\begin{abstract}
The present research has the central objective of understanding how dialogical psychotherapy, from the perspective of the Theory of Subjectivity, can mobilize new symbolic-emotional processes that favor the subjective development of children. Subjective Development is a complex and singular phenomenon, configured subjectively over time, from the different subjective meanings that emerge and take shape in the relationship with the other, marked by the individual's ability to generate new subjective productions that lead him to open up paths and possibilities to live your experiences. A case study was carried out that made it possible to understand the subjective configurations of the child in psychotherapy, generating intelligibility about the changes and new subjective productions throughout this process. Qualitative Epistemology served as the basis for González Rey's Theory of Subjectivity, in a cultural-historical perspective, guiding this work in the production of knowledge that occurred in a constructive-interpretative way. The interpretative analysis of the case showed the subjective character of the relationships built in the psychotherapeutic space and the possibility of the child's subjective development.

Key-words: subjectivity; psychotherapy; child development; subjective development.
\end{abstract}

* Mestre em Psicologia da Saúde pelo Centro Universitário de Brasília - UniCEUB

** Doutora pela Universidad San Carlos de Guatemala (2009) e mestrado em Psicologia pela Universidade de Brasília (1998). Professora do Centro Universitário de Brasília - UniCEUB.

${ }_{* * *}^{*}$ 'Doutora em Psicologia e Sexologia pela Universidade Católica de Louvain, Bélgica; Fullbright Scholar na St. John's University, New York, Estados Unidos. Pós-doutorada na Universidade de Tübigen, Alemanha. Professora Emérita da Universidade de Brasília, UNB. 


\section{Introdução}

Com o intuito de compreender como a psicoterapia dialógica pode mobilizar novos processos simbólico-emocionais que favoreçam o desenvolvimento subjetivo da criança, a Teoria da Subjetividade de González Rey foi escolhida como principal aporte teórico para fundamentar a presente pesquisa, para a qual, o indivíduo nos seus processos subjetivos, é permeado pelo contexto histórico-cultural, sendo único em suas experiências, constituído pela subjetividade social, assim como também a constitui, e por compreender o desenvolvimento subjetivo em sua complexidade e singularidade, ou seja, não reduzido a aspectos cognitivo-intelectuais, motores ou exclusivamente emocionais.

O estudo da subjetividade contribui para compreensão da emoção "como parte essencial dos processos humanos criadores desse mundo de ficção" (González Rey \& Mitjáns Martínez, 2017a, p. 23), pois ela deixa de ser vista como resultado das experiências vividas e, sempre atrelada ao simbólico, passa a ser parte constitutiva dos processos subjetivos configuradores do desenvolvimento subjetivo do indivíduo ou grupo.

A Teoria da Subjetividade permite compreender a criança em psicoterapia como um indivíduo complexo, único, gerador de processos subjetivos e configurado subjetivamente por seus processos simbólicos e emocionais, além de dar visibilidade e valor aos fatores da subjetividade social que fazem parte da constituição subjetiva dessa criança. Isso significa não vê-la a partir da queixa dos pais ou da escola, ou a partir de um comportamento específico, mas buscar compreendê-la de forma mais ampla, como um ser complexo, constituído por processos subjetivos individuais e sociais.

A presente pesquisa estudou, no espaço psicoterapêutico, as produções subjetivas da criança, visto que esse é um tema em desenvolvimento na Teoria da Subjetividade. O aporte teórico em questão permite a compreensão e a construção do saber a respeito da organização subjetiva dos processos individuais e sociais que se configuram subjetivamente, a partir dos inúmeros sentidos subjetivos emergidos ao longo da história de vida da pessoa (González Rey \& Mitjáns Martínez, 2017a). Essa produção de conhecimento se dá pela construção e interpretação elaboradas pelo próprio pesquisador no curso da pesquisa, segundo orienta a Epistemologia Qualitativa desenvolvida pelo mesmo autor, a qual norteia o curso da pesquisa a partir de três principais pressupostos: o caráter construtivo-interpretativo da produção de saber, o valor do singular como fonte legítima de conhecimento e a comunicação dialógica como principal via de acesso ao universo subjetivo.

A lógica de construção e interpretação da informação por parte do pesquisador, se desdobra em um processo chamado de lógica configuracional (González Rey, 2005, 2017a), ou seja, a construção interpretativa acontece junto com a organização dos pensamentos do pesquisador que integra diversas informações, provenientes de inúmeros instrumentos, ao longo de todo processo de pesquisa. Essa lógica configuracional permite articular momentos da vida da pessoa que parecem desconexos, mas que convergem no processo complexo e contraditório do desenvolvimento subjetivo (González Rey, 2007).

Desde muito cedo, as crianças já se organizam a partir das emoções emergentes nas relações com o outro, que são integradas às suas próprias produções simbólicas e, apesar dos poucos anos de vida e poucas vivências, formam uma bagagem simbólica complexa. À medida que se desenvolvem em diversos aspectos da vida, as produções simbólico-emocionais se tornam mais variadas e aumentam em complexidade. Esses sentidos subjetivos, que são a unidade simbólico-emocional, se organizam em configurações subjetivas. Entende-se como configuração subjetiva "um momento de auto-organização que emerge no fluxo caótico de sentidos subjetivos e que define o curso de uma experiência de vida" (González Rey \& Mitjáns Martínez, 2017a, p.52), ou seja, é uma produção subjetiva a partir dos sentidos subjetivos convergentes, da qual também emergem novos sentidos subjetivos que podem modificar outras configurações subjetivas. Isso revela a dinamicidade desse fenômeno, o qual se destaca por sua continuidade e não linearidade, expressando a subjetividade humana como um processo.

Esse modelo de pesquisa conta com a participação ativa e o engajamento emocional do pesquisador, contrariando a ideia hegemônica da neutralidade dele durante esse processo. O destaque da Epistemologia Qualitativa está exatamente ao considerar o caminho percorrido pela pesquisa como relacional, sabendo que a construção teórica a respeito dos sentidos subjetivos e configurações subjetivas por parte do pesquisador, não se dá a partir de informações isoladas, mas por um complexo processo de integração de distintas informações verbais e não-verbais que emergem desse espaço dialógico (González Rey \& Mitjáns Martínez, 2017a).

O engajamento emocional do psicoterapeuta com a pessoa em psicoterapia, tanto com crianças quanto com adultos, é ação necessária e essencial para a produção de ideias por parte do pesquisador (González Rey \& Mitjáns 


\section{DE DESENVOLVIMENTO SUBJETIVO INFANTIL}

Martínez, 2017a), pois é por meio do diálogo que o psicoterapeuta aprofunda no conhecimento da história de vida da pessoa, sendo-lhe possível levantar hipóteses e provocar reflexões.

Através do diálogo, "não só podemos produzir hipóteses sobre a forma pela qual o participante sente aspectos da sua vida, mas também podemos gerar ações que podem ser facilitadoras de reflexões da pessoa sobre esses mesmos aspectos da sua vida", (Mori, 2020), assim, a partir dessa autonomia, o psicoterapeuta pode percorrer um caminho que possibilita gerar uma ciência ética que respeita o individual e o social.

Este modelo de pesquisa, exclui "o determinismo e abre caminho a processos explicativos do nível individual" (González Rey \& Mitjáns Martínez, 2017a, p. 42), a partir dos quais, a pesquisa se desenvolve na medida em que surgem os processos subjetivos do indivíduo, nas suas mais diversas expressões e, assim, o pesquisador constrói gradualmente as informações mediante os indicadores que emergem durante a pesquisa. Esses indicadores também são produções teóricas do próprio pesquisador (González Rey \& Mitjáns Martínez, 2017a) e, ao longo do processo construtivo e interpretativo, vão convergindo e se desdobrando em hipóteses mais amplas acerca do problema.

\section{Teoria da subjetividade e desenvolvimento subjetivo}

A subjetividade caracteriza os processos humanos dentro das condições culturais e históricas da vida de cada um, considerando indissociável o indivíduo do social, pois a subjetividade individual é constituída com a social, assim como a social se constitui com a individual, concomitante e continuamente (González Rey, 2015). Se torna possível conhecer mais sobre determinada cultura local a partir da compreensão das produções subjetivas dos indivíduos que dela participam, pois todos os sistemas dos quais a pessoa faz parte (como o familiar, profissional e acadêmico) se configuram a partir da maneira como ela produz subjetivamente perante a eles, ou seja, a subjetividade vai se organizando nesses diferentes espaços. Portanto "a subjetividade social tem, nos sistemas de relações e nas produções subjetivas sociais e individuais, os recursos essenciais de seu desenvolvimento" (Mitjáns Martínez, 2020). Isso ocorre ao longo de toda a história de vida da pessoa, se traduzindo no modo de perceber a si mesma, o outro e seu lugar no mundo.

Isso nos leva a entender que, diante de um mesmo acontecimento, cada pessoa subjetiva de modo único e singular, destacando, assim, outra relevância da teoria da subjetividade para a presente pesquisa, por colocar a pessoa no lugar de geradora de novos processos, em vez de ser subordinada a fatores externos. A criança, por exemplo, inserida em determinada cultura, produz inúmeros sentidos subjetivos na sua relação com o outro, possibilitando que este tome forma simbólica-emocionalmente na sua história. Assim, a partir das produções subjetivas mobilizadas nessa relação, vão se configurando diferentes sentidos subjetivos que serão constituintes da sua maneira de viver futuras experiências.

Compreender o caráter ativo e gerador dos sentidos subjetivos nos processos de desenvolvimento infantil, implica pensar a criança como protagonista em sua história, em vez desta ser resultado da influência de outros processos. Os processos subjetivos são dinâmicos e recursos criativos do indivíduo para lidar com as questões mais objetivas da vida (González Rey \& Mitjáns Martínez, 2017b), ou seja, a pessoa não é vítima dos acontecimentos externos a ela, pois tem a possibilidade de gerar novos recursos subjetivos frente à essas vivências.

A cultura, por si só, não é determinante para o desenvolvimento, porém, "em unicidade com as emoções, constitui uma base para produção de processos e formações subjetivos" (Rossato \& Assunção, 2019, p. 53), destacando, assim, o indivíduo como protagonista em seu desenvolvimento.

Ao falar de desenvolvimento humano, a teoria da subjetividade apresenta a categoria do desenvolvimento subjetivo como uma alternativa de gerar inteligibilidade aos processos complexos e singulares da pessoa, sem fragmentá-lo em dimensões ou etapas, além de diferenciá-lo de outros conceitos de desenvolvimento relacionados, predominantemente, à compreensão do psíquico, do biológico ou do comportamental. O desenvolvimento subjetivo é uma produção humana, singular, contraditória, irregular, sem estágios e imprevisível (González Rey \& Mitjáns Martínez, 2017a).

Segundo González Rey e Mitjáns Martínez (2017a), o desenvolvimento subjetivo constitui-se com o surgimento de novas configurações subjetivas em determinada área da vida da pessoa, a partir dos múltiplos processos subjetivos, "e que lhe geram um envolvimento pessoal cada vez mais profundo na área em que a configuração subjetiva do desenvolvimento se organiza" (Mitjáns Martínez \& González Rey, 2017, p.23).

De acordo com Rossato e Assunção (2019, p. 47) "o desenvolvimento subjetivo se dá quando novas produções, geradas no tensionamento das ações e relações vividas, ganham força e relativa estabilidade, possibili- 
tando reconfigurações no sistema e abrindo caminhos qualitativamente diferenciados de produções subjetivas". Portanto, diz respeito à capacidade do indivíduo gerar novas produções subjetivas que possibilitam a emergência de formas inéditas de vivenciar suas experiências em determinados momentos, de forma mais estável.

Segundo Madeira-Coelho (2020, p.114), “o desenvolvimento subjetivo implica tanto a dinâmica que relaciona momentos atuais ao contínuo fluxo da vida, quanto a configuração singular de processos simultaneamente individuais e sociais, plenos de impactos e rupturas, mas que resultam em novas estabilidades". Diversos processos subjetivos podem ser geradores de novas configurações subjetivas, porém, o desenvolvimento subjetivo implica mudança no sistema de configurações subjetivas, seja por meio de uma reorganização subjetiva ou pela emergência de uma nova configuração (González Rey, 2007).

Esse desenvolvimento "não é um processo progressivo, ordenado, nem linear, mas um processo contraditório, que gera forças subjetivas em conflito" (González Rey \& Mitjáns Martínez, 2017a, p.157), a partir das quais surgem novas expressões das configurações subjetivas associadas a determinado contexto, favorecendo o indivíduo se posicionar como agente em sua própria história.

Os conceitos de sentido subjetivo e configuração subjetiva permitem um olhar dinâmico e integrador sobre esse processo de desenvolvimento. Esse conceito nos leva a pensar o desenvolvimento humano como um processo em constante movimento, fora de padrões universais, assumindo sua singularidade e sempre associado a mudanças que podem favorecer novos níveis de organização subjetiva (Muniz \& Mitjáns Martínez, 2019).

Em toda nova experiência significativa da vida, emergem produções subjetivas que podem ou não levar a momentos de desenvolvimento subjetivo. Esse processo não é percebido de forma imediata ou por comportamentos momentaneamente observáveis, pois, como falado anteriormente, uma mudança pontual ou esporádica não implica em desenvolvimento. Tampouco se percebe esse processo por atitudes classificadas socialmente ideais, pois, ações aparentemente incoerentes, ou caracterizadas como sofrimento, por exemplo, podem ser meios para novos sentidos subjetivos emergirem, acarretando o surgimento de recursos subjetivos passíveis de gerar desenvolvimento (González Rey \& Mitjáns Martínez, 2017b).

É importante destacar que o desenvolvimento da subjetividade se faz de forma processual e não como um acontecimento súbito e pontual. Segundo González Rey e Mitjáns Martínez (2017a, p.158), "é esse caráter vivo, contraditório e variável que faz do desenvolvimento da subjetividade um processo inseparável do contexto e da história dos indivíduos e permitindo sua compreensão como processo cultural, histórico e social", ou seja, um fenômeno complexo e singular que ocorre diferentemente em cada pessoa, não sendo possível prever ou categorizar.

Para compreender o desenvolvimento subjetivo de uma criança, é necessário considerar a criança que está além do diagnóstico médico definido a partir de suas expressões e comportamentos, adentrando, assim, no conhecimento dos seus processos subjetivos que integram o vivido. Segundo Oliveira (2017, p. 21), a não compreensão desses processos leva à desconsideração da singularidade em prol da padronização pelos mais diversos modelos teóricos, excluindo "manifestações que são geradas em tramas sociais muito distintas do contexto em que o conhecimento foi produzido, ignorando igualmente as produções subjetivas diversas das crianças que vivem em contextos sociais diferentes".

As relações dialógicas contribuem para o desenvolvimento subjetivo do indivíduo por implicarem engajamento, podendo ser a partir de expressões que demonstrem valor, interesse e participação, ou geradoras de tensões, contradições e rupturas, sendo ambas extremamente necessárias e essenciais para que a criança encontre possibilidades de ser sujeito em suas próprias vivências (González Rey \& Mitjáns Martínez, 2017a).

O conceito de sujeito, da Teoria da Subjetividade, foi desenvolvido com o intuito de superar a ideia determinista de personalidade e gerar maior compreensão dos processos humanos (Mitjáns Martínez, 2020), representando, assim, o indivíduo que "abre uma via própria de subjetivação, que transcende o espaço social normativo dentro do qual suas experiências acontecem, exercendo opções criativas no decorrer delas, que podem ou não se expressar na ação" (González Rey \& Mitjáns Martínez, 2017a, p.73).

Ser sujeito é ter um papel ativo, emocional e intencional diante das decisões em sua vida, com seus próprios critérios e recursos subjetivos, participando e envolvendo-se nas experiências que o cercam e, principalmente, abrindo novos caminhos de produções subjetivas nas experiências vividas.

O processo de desenvolvimento da subjetividade não é constante ou contínuo em termos de temporalidade, e pode ocorrer em uma área da vida da criança, por exemplo a escolar, e não ter a mesma qualidade de expressão em outra área, como a familiar. O desafio, portanto, com a criança, é mobilizá-la de modo que, criativamente, ela 
possa gerar novos caminhos dentro dos contextos sociais nos quais está inserida. Como que criativamente ela pode produzir alternativas como sujeito de sua história? Acredito que através de sua principal forma de comunicação: a brincadeira. Segundo Winnicott (1975, p.80), “o brincar é essencial porque nele o paciente manifesta sua criatividade", ou seja, é também no brincar que a criança vivencia novas experiências e produções subjetivas, favorecendo a emergência da sua condição de sujeito diante do vivido.

O diálogo, como processo subjetivo, ocorre quando os indivíduos envolvidos se engajam e passam a subjetivar essa relação, pois, somente assim, haverá "reflexões configuradas subjetivamente, sem as quais o próprio diálogo não irá acontecer" (González Rey \& Mitjáns Martínez, 2017a, p. 29). Entretanto, o diálogo não é determinante do desenvolvimento subjetivo, mas possibilita a abertura de espaço para a emergência de novos sentidos subjetivos que, por sua vez, podem transformar as configurações subjetivas dos indivíduos dessa relação e favorecerem desenvolvimento (González Rey \& Mitjáns Martínez, 2017a).

Para se compreender as expressões emocionais e simbólicas da criança, torna-se necessário conhecer sua história tanto quanto os contextos sociais dos quais ela participou e ainda participa, pois somente com o conhecimento de suas particularidades e vivências, torna-se possível gerar inteligibilidade acerca de suas configurações subjetivas que não dizem respeito somente a uma única ou atual experiência, mas a uma rede de produções subjetivas em diversos momentos de sua história. Tanto a subjetividade social da família quanto a da sociedade, atravessam as produções subjetivas da criança, acarretando diferentes efeitos na forma como ela representa seu mundo.

Considerando, portanto, que o desenvolvimento da subjetividade pode se constituir nos diversos momentos da vida da criança, como o espaço psicoterapêutico dialógico infantil pode representar um desses momentos favorecedores de tal processo?

\section{Psicoterapia dialógica - cenário favorecedor de desenvolvimento subjetivo infantil}

A psicoterapia caminhou, por muito tempo, como um espaço de reprodução de modelos teóricos dominantes, negligenciando a possibilidade de reflexão crítica a respeito dessas teorias. A atuação clínica limitou-se por muitos anos à aplicação de conceitos e técnicas definidas a priori, não aprofundando na investigação singular da história do indivíduo, tampouco buscando compreensão de suas configurações subjetivas construídas por uma multiplicidade de fatores.
É comum pais chegarem ao consultório psicoterapêutico angustiados, preocupados, esperando do psicólogo orientações e conselhos de como devem atuar para mudar a criança. Essa é uma característica dominante da subjetividade social à respeito do papel do psicoterapeuta, como se sua prática fosse direcionada a "submeter o outro a um saber que orienta uma forma de viver a vida" (Mori \& Goulart, 2019, p. 4). Os pais esperam orientações do psicoterapeuta à respeito de suas funções e para a criança que é considerada leiga quanto às suas experiências de vida, como se vivesse a partir das influências do meio no qual está inserida passivamente.

O modelo construtivo-interpretativo rompe com a ideia hegemônica de a psicoterapia ser uma prática que lida com transtornos e patologias, visto que não segue um protocolo de análise e dá, ao pesquisador ou psicoterapeuta, a autonomia reflexiva de compreender o caso mediante construções teóricas a partir dos processos subjetivos configurados no indivíduo, de forma singular. Como esclareceu Neubern (2012), a atenção do profissional deve estar para além dos transtornos ou diagnósticos, voltando-se para os processos subjetivos e tramas sociais da pessoa, com o intuito de alcançar maior compreensão da forma como ela subjetiva o seu mundo.

Diante disso, compreendemos que a psicoterapia infantil não acontece a partir de um manual que deve ser seguido e cumprido para alcançar um resultado definido, pois ela é um processo subjetivo, individual, sem roteiro, que se desenvolve a partir da relação dialógica entre o psicoterapeuta e a criança, com o objetivo de mobilizar produções subjetivas a partir do lúdico. O Outro é significativo no desenvolvimento da criança somente quando passa a ser subjetivado por ela, portanto, a relação psicoterapêutica dialógica infantil, quando passa a ser subjetivada, pode se tornar esse outro favorecedor de produções subjetivas que oportunizem um desenvolvimento subjetivo.

Essa relação autêntica e sincera entre o psicoterapeuta e a criança é essencial para que o não dito possa vir à tona e possibilite a compreensão sobre as configurações subjetivas em sua vida. $\mathrm{O}$ envolvimento do psicoterapeuta implica assumir riscos ao expor suas vulnerabilidades e lidar com a imprevisibilidade, além de favorecer um ambiente que possa ser subjetivado como seguro para liberdade de jogo. Se a criança se sente segura no espaço dado, ela se expressa nas brincadeiras, nos jogos e nas conversas, por meio de suas ações, palavras e, até mesmo, pelo silêncio.

$\mathrm{Na}$ psicoterapia infantil, o psicoterapeuta precisa descobrir a linguagem da criança e buscar engajar-se 
com aquilo que atrai sua atenção, buscando entrar em seu universo com palavras, brincadeiras e histórias que lhe interessem. Segundo González Rey, Goulart e Bezerra (2016, p. s60), “o afeto gerado na comunicação é essencial em qualquer atividade orientada ao desenvolvimento subjetivo da criança. Sem um espaço de socialização em que a criança se sinta acolhida e segura, o desempenho dela em qualquer atividade estará comprometido”.

É importante ressaltar que essa comunicação com a criança se dá de forma bem diferente da realizada com adultos no contexto da psicoterapia. Apesar de haver a comunicação verbal, na maioria das vezes, a criança está em todo tempo imersa em alguma brincadeira, jogo, fantasia, e conta ao psicoterapeuta sua história, suas angústias, seus medos, inseguranças, alegrias e conquistas, através desse brincar, de forma intencional ou não. Aqui se torna essencial a capacidade do psicoterapeuta de compreender o 'como' e 'o quê' a criança está tentando comunicar, interpretando sua linguagem que, frequentemente, é não-verbal.

De acordo com González Rey e Mitjáns Martínez (2017a p.22), “a subjetividade humana é inseparável do mundo simbólico da cultura dentro do qual ela emerge, mas ela não se reduz à linguagem, nem ao texto, nem ao discurso...", pois, a subjetividade não está nas palavras. A psicoterapia infantil se desenvolve mediante essa capacidade do psicoterapeuta compreender processos subjetivos da criança, ou seja, suas construções simbólicas e emocionais em diversas áreas da vida e, através das brincadeiras, favorecer mobilizações subjetivas que a permitam gerar novas formas de sentir e simbolizar suas vivências e relações.

Quando o pesquisador se torna sujeito do processo de pesquisa, consegue ver além daquilo que é expressado, dando vazão à sua criatividade para levantar conjecturas que serão sustentadas ou modificadas ao longo desse processo. Esse tipo de relação é, portanto, essencial para o desenvolvimento subjetivo da criança em psicoterapia que precisará encontrar esse vínculo no psicoterapeuta, como o outro significativo que demonstre igual interesse na construção dessa relação.

A relação dialógica entre o psicoterapeuta e a criança não se define apenas por uma atenção especial, escuta diferenciada e acolhimento, mas por uma relação que objetiva o favorecimento do desenvolvimento subjetivo do outro, mobilizando processos subjetivos e ações criativas, superando quaisquer limites na comunicação (González Rey \& Mitjáns Martínez, 2017a). As relações de engajamento com afeto, compreensão e escuta, favorecem a emergência de recursos subjetivos de segurança, autoconfiança, pertencimento, dentre outros, tão essenciais à maior parte das crianças e adolescentes por estarem em um processo intenso de desenvolvimento (Muniz, 2019).

A imaginação e a fantasia, fundamentais para o desenvolvimento infantil, se expressam através do envolvimento emocional que a criança tem ao viver uma relação onde é levada a sério, em um espaço onde brincar também é coisa séria. Winnicott (1982) fala sobre a importância de um ambiente emocionalmente estável para a criança, com o qual consiga se identificar, para gerar progressos graduais no seu desenvolvimento. Esse ambiente pode ser oportunizado em sua própria casa, na escola, na psicoterapia, na casa dos avós ou outros espaços.

A psicoterapia infantil acontece basicamente por meio de brincadeiras, por que o brincar é mais do que uma ferramenta que favorece a expressão, é também um momento de construção de si mesmo. É no brincar que a criança experimenta inúmeros papéis sociais e sentimentos diversos, como alegria, tristeza, raiva, sucesso, realizações de sonhos, além de reproduzir momentos vividos por ela ou por outros, que as mobilizem subjetivamente de forma que as permitam sentir e simbolizar diferentemente situações de angústias, medos e inseguranças. Segundo Vygotsky (2009, p. 99), "a brincadeira é a escola da vida para a criança, educa-a espiritual e fisicamente. Seu significado é enorme para formação do caráter e da visão de mundo do futuro homem". O brincar permite à criança reproduzir, reviver e representar o que foi visto, vivido e sentido, mobilizando seus processos subjetivos.

Sobre a brincadeira, Winnicott (1975, p. 63) disse, ainda, que ela "é universal e que é própria da saúde; o brincar conduz aos relacionamentos grupais; o brincar pode ser uma forma de comunicação em psicoterapia". O mesmo autor refere-se à brincadeira no contexto psicoterapêutico como sendo sempre uma experiência criativa, que consome o espaço e o tempo de maneira intensa e real para a criança, devendo ser sempre um brincar espontâneo e não submisso.

As experiências vividas pela criança através das brincadeiras, enriquecem sua capacidade de desenvolver seus próprios critérios para tomadas de decisões, expressar suas preferências, suas vontades e suas escolhas. De acordo com Winnicott (1982, p. 163), “a brincadeira é a prova evidente e constante da capacidade criadora, que quer dizer vivência", é a evidência da condição da criança como geradora e produtora de sua subjetividade.

$\mathrm{Na}$ psicoterapia infantil, a criança expressa com palavras, sons, atitudes, gestos, expressões faciais, falas 
de personagens, estórias inventadas, fantasias e encenações, suas emoções e seus pensamentos. O maior desafio do psicoterapeuta infantil é engajar-se na atividade sem perder seu olhar investigativo, com o intuito de mobilizar subjetivamente a criança e favorecer a emergência de novos sentidos subjetivos, de um jeito lúdico e adequado à sua linguagem.

Falar de psicoterapia infantil implica falar de um processo psicoterapêutico também com a família dessa criança. Desde o primeiro encontro com os pais (cuidadores, responsáveis), essa relação psicoterapêutica dialógica começa a se formar, pois, diversos sentidos subjetivos de confiança, transparência, autenticidade, lealdade, compromisso, podem ser gerados e, processualmente, configurados na relação família - psicoterapeuta.

Podemos considerar que esses pais são, também, continuamente mobilizados em seus processos subjetivos, podendo, inclusive, alcançarem momentos de desenvolvimento subjetivo no curso da psicoterapia de seu filho, quando há o engajamento de todos ao longo do processo.

\section{O estudo de caso: Caso Léo}

Léo $^{1}$ tinha 6 anos no período de realização dos atendimentos, morava com seus pais, Tatiana e Paulo, e seu irmão de 6 meses, Daniel. Mudaram de cidade há poucos anos e, assim, se distanciaram dos demais familiares.

Tatiana, a mãe, procurou a psicoterapia para Léo com a queixa de que ele não sabia expressar verbalmente o que sentia, se tornando uma criança muito chorona, como ela mesma disse, em diversas situações.

Tatiana: Ele tem chorado demais. Chora todos os dias para ir à escola, quando quebra ou suja alguma coisa em casa, quando outras crianças não querem brincar com ele... tudo ele chora. Chora muito, de verdade, não é manha, é choro de sair lágrima mesmo. O que mais tem me preocupado é o excesso de choro para ir à escola ${ }^{2}$, porque não sei se está acontecendo alguma coisa lá com ele...

Psicoterapeuta: E você consegue dizer quando esse excesso de choro começou?

Os nomes utilizados nessa pesquisa, referentes aos participantes, são fictícios para assegurar o sigilo e privacidade das identidades pessoais dos mesmos.

2 Fazer uma visita à escola, observar a criança com os colegas e conversar com os professores, seria enriquecedor para a construção da informação do caso pesquisado. Entretanto, não foi possível realizar esse encontro, pois a coordenação estava passando por mudanças e a nova coordenadora disse que precisaria se familiarizar do caso antes de conversar. $\mathrm{Na}$ segunda tentativa, meses depois, ela não estava disponível e só era possível conversar com a professora na presença da coordenadora.
Tatiana: Ele chorou muito quando era pequenininho para se adaptar à escola. Foram meses. Mas agora começou de novo no início desse ano. Até o ano passado ele ia feliz.

O início desse ano foi marcado com o nascimento do irmão, acarretando grandes mudanças na dinâmica familiar. Daniel nasceu com um quadro de refluxo severo, então não podia se deitar, ficando somente na posição vertical. Como não podia dormir deitado, tanto de noite quanto de dia, dormia no colo de Tatiana. Ela tinha medo de deixá-lo no bebê conforto ou cadeirinha, mesmo sendo permitido pelo pediatra, e acontecer alguma coisa, como ele vomitar, se engasgar e ela não perceber.

Tatiana: Acho que Léo deve ter sentido um pouco, porque eu ficava o tempo todo com ele... Mas agora, de tarde, tenho que ficar no quarto pro Daniel dormir no meu colo, trancada lá. Não posso colocar ele pra dormir e aproveitar para dar atenção pro Léo como deveria... então ele acaba ficando muito sozinho. Porque se fico na sala, Daniel não dorme com o barulho do Léo.

Psicoterapeuta: E como era antes do Daniel nascer?

Tatiana: A gente ficava sempre junto. Eu trabalhava só um período, na hora que ele estava na escola, e o resto do dia ficávamos juntos. Mas, depois que o Daniel nasceu, não posso deixar ele. Mesmo assim Léo ama o irmão. Ama demais. Faz carinho, beija... ele nunca teve ciúmes.

\section{Psicoterapeuta: E o pai dele?}

Tatiana: Ele trabalha o dia todo, então também não consegue dar muita atenção pra ele. Mas, quando chega à noite, fica com o Léo para eu poder cuidar do Daniel.

Segundo o pai de Léo, Tatiana era sempre exagerada em suas preocupações, por exemplo, quando percebia uma manchinha na pele já pensava ser um câncer de pele e agendava consultas médicas para investigar.

Paulo: Outro exemplo que posso te dar, foi de quando Léo era mais novinho, uns 2 anos, Tatiana achava que ele interagia pouco com outras pessoas, aí começou a pesquisar sobre esse sintoma e concluiu que nosso filho tinha autismo. Ela procurou profissionais para nos orientar, participamos de grupos de apoio às famílias com crianças autistas durante um tempo, colocou Léo em psicoterapia, mas como não teve confirmação do diagnóstico 
e não percebia melhora em Léo, ela acabou deixando de participar do grupo e tirou Léo da psicoterapia.

Tatiana parecia tentar controlar todas as coisas de forma que ficassem do jeito que ela considerasse ideal. Sua preocupação sobre Léo não socializar, na verdade, representava sua própria visão de mundo, assim como Daniel ter que ficar 24 horas em seu colo, durante meses, passava, também, pela sua representação de maternidade. Isso nos sugere que ela parecia querer colocar o outro, seus filhos e marido, como foi interpretado após uma conversa com ele, dentro de suas representações.

Essas representações, na verdade, passam por questões da subjetividade social. Aqui no Brasil, por exemplo, ainda há uma representação subjetiva social dominante quanto ao papel da mãe, que deve ser protetora, presente e assumir a maior parte dos cuidados referentes aos filhos.

O trecho abaixo, retirado de uma conversa com Tatiana, aponta, assim como os trechos anteriores, para o indicador de excesso de preocupação e controle por parte dela:

Tatiana: Ele (Léo) também sofre muito com despedidas. Como não temos parentes por aqui, sempre que vem alguém ficar um tempo na nossa casa e vai embora, ele sofre demais. Minha mãe está lá em casa esse mês e vai embora semana que vem. Já falei pra ela: “mãe, a senhora quando for embora não vai se despedir. Vai embora sem ele perceber!" O que você acha? Assim é pior ou melhor?

Psicoterapeuta: Ela ir embora já vai fazê-lo sofrer, pelo que você relatou. Mas ela ir embora sem dar tchau, você não acha que pode parecer um abandono, parecer que ela não se importou, que ela não fez questão de se despedir? Ele sofre porque sabe que passará muito tempo sem reencontrá-la e sentirá saudades. Provavelmente, você também sofre, mas por ser adulta, já tem mais recursos para lidar com essa dor. Ele ainda está aprendendo e cada nova experiência dessa, o ensina mais.

Tatiana: Você está certa. É tão ruim vê-lo chorar, mas acho que ele choraria de toda forma quando soubesse que ela se foi...

Nessa conversa, construímos o indicador de sentidos subjetivos relacionados ao controle das situações que expressavam a dificuldade dela em lidar com a fato de estar longe da família. Tatiana parecia querer controlar a forma como o filho vivia suas experiências. A dificuldade em lidar com o sofrimento do filho, expressava a dificuldade dela em lidar com o próprio sofrimento. É compreensível o desejo da mãe de não querer ver seu filho sofrer, porém, algumas dessas experiências apresentam à criança a forma como o mundo se configura e a inserem em vivências que favorecerão a emergência de novos recursos subjetivos, porém, isso só é possível quando os pais também fizeram esse caminho, pois, como conduzir o outro por um percurso desconhecido?

Também podemos perceber que Tatiana já subjetivava a figura da psicóloga como um outro significativo, quando perguntava sua opinião e concordava com o que foi falado. A forma como o psicoterapeuta é subjetivado importa para a qualidade da relação de confiança que se estabelece no contexto da psicoterapia.

Outro trecho retirado da primeira conversa com Tatiana, que chamou atenção, foi quando ela disse: "não posso deixá-lo (Daniel). Mesmo assim, Léo ama o irmão, ama demais, faz carinho, beija... nunca teve ciúmes". Paulo, o pai, falou a mesma coisa em outra conversa: "O Daniel demanda muito... Léo não tem ciúmes, ele adora o irmão. Mas ele sente que tem algo diferente, essa questão da atenção, do irmão ter muito mais da nossa atenção do que ele..."

Percebemos que Léo tinha, sim, ciúmes de seu irmão e que, na verdade, Tatiana e Paulo verbalizavam seu desejo de que isso não fosse real. Podemos afirmar que esses pais não legitimavam a forma como seu filho sentia suas experiências. Esse é um ponto extremamente importante para refletirmos, pois vemos como os pais podem mobilizar processos subjetivos contraditórios nos seus filhos por não saberem lidar com suas próprias contradições. Tatiana expressava dificuldade em lidar com sentimentos de insegurança, medo, perda e, dessa forma, ela também não conseguia lidar com a realidade de seu filho estar vivendo experiências que mobilizavam sentidos subjetivos que se expressavam com o medo e a insegurança.

A chegada de um irmão sempre muda a dinâmica familiar de alguma maneira e, geralmente, a atenção dos pais passa a ser dividida, porém, essa experiência pode ser mais facilmente vivida dependendo da forma como os pais lidam com os sentidos subjetivos emergentes ao longo desse processo. No caso de Tatiana, ela parecia estar sofrendo com o fato de estar sem familiares por perto, se sentindo sozinha na cidade e não percebia o quanto o seu sofrimento impactava também seu filho.

Nos momentos à sós com Léo, interpretamos que havia sentidos subjetivos contraditórios referentes ao irmão e à mãe, uma disputa não consciente pela atenção 


\section{DE DESENVOLVIMENTO SUBJETIVO INFANTIL}

dela. Ele produzia sentidos subjetivos de ciúmes, mas parecia não se permitir expressá-los por não ter essa "permissão" ou um acolhimento por parte de seus pais.

Psicoterapeuta: Vi que tem um neném lá fora que fica o tempo todo sorrindo para você...

Léo: Meu irmãozinho.

Psicoterapeuta: Ah, que legal! Ele parece gostar muito de você... percebi que toda vez que você olhava pra ele, ele sorria para você.

Léo: É. É Verdade.

Psicoterapeuta: Ele já consegue brincar com você?

Léo: Ainda não. Ele é muito pequeno.

Psicoterapeuta: E vocês dormem juntos no mesmo quarto?

Léo: Não. Ele dorme com minha mãe, no colo dela. $\mathrm{Na}$ poltrona. Ele não pode deitar.

\section{Psicoterapeuta: Por quê?}

Léo: Ele pode se engasgar. E morrer. (Fala olhando para o chão). casa?

Psicoterapeuta: E quem brinca com você na sua

Léo: Ninguém. Só minha cachorra.

Psicoterapeuta: E seu pai?

Léo: Ele trabalha...

Psicoterapeuta: Você se sente sozinho?

Léo: Não... minha mãe precisa cuidar dele.

Tatiana não permitia que Léo vivesse o ciúme em relação ao irmão e, assim, ele ficava inseguro em relação ao que realmente sentia, expressando essas contradições através do choro tão frequente. Temos um relato explícito dele parecer aceitar a ausência da mãe por compreender que ela precisasse cuidar do seu irmão. Porém, a forma como ele subjetivava esse contexto não era permeado por compreensão, mas por muita contradição.

Tatiana contou que sempre que ele quebrava algo ou sujava, já chegava chorando para contar, pedindo desculpas várias vezes: "a gente nem briga, mas ele conta chorando como se estivesse com medo da nossa reação" - vemos aqui, novamente, outro exemplo que reforça o indicador de sentidos subjetivos expressados pelo medo e insegurança frente a essa nova configuração familiar, já que o mundo que ele conhecia, não existia mais. Essa situação nos mostra que a configuração subjetiva da relação com a mãe estava em transformação, a partir dos novos sentidos subjetivos emergentes em relação à ela. A mãe que ele teve durante seus primeiros cinco anos de vida, já não era mais a mesma. Sua insegurança e medo, expressados através do choro frequente, diziam respeito ao luto que ele estava vivendo diante da perda daquela mãe.

Sobre a dificuldade de Léo em lidar com essas experiências de fracasso, quando errava, quebrava ou sujava algo, Léo parecia não ter recursos subjetivos para lidar com a situação, expressando fragilidade frente às adversidades, chorando e se sentindo culpado. Entretanto, ele não era o único responsável pelo seu mal-estar, pois as dificuldades dos pais também eram configuradoras desse processo.

Os adultos têm grande importância no desenvolvimento da criança, pois, a relação que desenvolvem é configurada a partir dos sentidos subjetivos emergentes em todos os envolvidos, ou seja, as inseguranças, limitações e dificuldades dos pais, também são configuradoras dos processos subjetivos dos filhos. Tatiana expressava dificuldade em lidar com essas emoções conflitivas, de perda, de mudanças e essa dificuldade não facilitou o caminho para Léo viver essas novas experiências.

Ele expressava não ter uma relação positiva com os erros, pois, ao invés de percebê-los como uma possibilidade de aprendizado e apresentar autonomia para corrigi-los, sofria por ter errado, se desculpava e esperava a ajuda de um adulto para solucionar a questão. Essa reação passava por produções subjetivas historicamente constituídas e associadas às outras experiências vividas no contexto social familiar, talvez de punições, cobranças ou rigor. $\mathrm{O}$ trecho a seguir, retirado de uma sessão que fizemos massinha caseira, sustenta a construção dessa hipótese:

Psicoterapeuta: Agora pode ir mexendo com essa colher. Quando começar a ficar mais dura, você pode misturar com a mão.

Léo me olha com os olhos arregalados. 
Léo: Com a mão?!

Psicoterapeuta: Isso. Com a mão. Até tudo ficar bem misturado e macio. Você amassa uma parte e eu amasso outra, aí ela fica pronta rapidinho para a gente brincar.

Léo continuou misturando com a colher e quando falei para pegar com as mãos ele só encostou as pontas dos dedos e disse:

Léo: Gruda, né?

Psicoterapeuta: É, gruda um pouco, mas é só a gente colocar farinha. Fica igual massinha de verdade.

Continuou sem colocar a mão e parecia bem incomodado com as pontas dos dedos sujas.

Psicoterapeuta: Você não quer colocar as mãos?

Léo: É, não... não quero.

Psicoterapeuta: Por quê?

Léo: Ah, sei lá... gruda muito.

Psicoterapeuta: Você não gosta de massinha que gruda?

Léo: Eu gosto de massinha, mas não gosto que grude. Por que fica sujo.

Psicoterapeuta: E por que não pode ficar sujo?

Léo: É... Ah, porque não é pra ficar sujo.

Psicoterapeuta: Você não pode se sujar?

Léo: É, não...

Psicoterapeuta: Quando você joga futebol você fica sujo, suado?

Léo: Fico sim.

Psicoterapeuta: E isso te incomoda?

Léo: Não.
Psicoterapeuta: E por que aqui você fica incomodado?

Léo: Ah, não sei... se eu sujar essa roupa minha mãe vai brigar.

Psicoterapeuta: Ah, ela briga se sujar a roupa? E a roupa do futebol, ela não briga?

Léo: É, isso.

Levando em consideração que a relação entre eles estava fragilizada, já que essa mãe estava sendo subjetivada como estranha ou desconhecida, Léo ficava ainda mais inseguro quando fazia algo que mobilizava nela a emergência de sentidos subjetivos de raiva e decepção.

$\mathrm{Na}$ primeira sessão com Léo, ele entrou na sala de atendimento muito quieto, andando de forma rígida, como um robô. Não mexeu em nada, não pegou nenhum brinquedo dos que estavam expostos e espalhados pelo consultório até que eu o autorizasse a pegar. A maioria das crianças dessa idade, ao ver tantos brinquedos por perto, já pega algum para ver, mexer, brincar, mas Léo apenas entrou na sala, sentou no chão e ficou olhando para todos os brinquedos.

Com esse nível de rigor, torna ainda mais compreensível o porquê dele chorar e se desculpar tanto quando fazia algo considerado errado.

Paulo: Quando era mais novinho (Léo), nunca ficava separado de nós, porque estranhava muito as pessoas. Mas, assim, ele só saía de casa até o corredor do prédio e na janela, ou saía mesmo quando ia ao médico. Passear de verdade ele já tinha mais de 6 meses de idade quando foi a primeira vez.

Psicoterapeuta: Por que ele não passeava antes?

Paulo: A mãe dele (sorrindo). Ela tinha medo de tudo. "Ah, vai pegar doença. Vai isso, vai aquilo..." Diferente do que é hoje com Daniel. A gente já até viajou com ele! Mas, com Léo, ela ficava com ele o tempo inteiro. Quando chegava visita em casa, ninguém podia pegar ele. Ela tinha ciúmes dele até comigo! Eu o pegava no colo e quando ficava cheirando no cangote dele, ela já dizia: "não pode, não pode, vai dar alergia..." e pegava ele de mim. Mas cinco minutos depois, ela fazia a mesma coisa com ele. 
Psicoterapeuta: E você falava isso pra ela?

Paulo: Eu falava. Só que ela tomava como se eu tivesse dando uma bronca... e não levava muito em consideração. Para evitar as brigas, eu deixava pra lá. Hoje eu acho que tem um pouco a ver com isso, porque querendo ou não, ela super protegeu ele. Ela não reconhece que exagera. Às vezes ela não confia nem em mim para tomar conta! Eu só saía sozinho com o Léo pequenininho se fosse para levar à escola. Mas para passear, só nós dois, não! Ela não deixava porque achava que era perigoso. A gente faz isso só agora, depois que o Daniel nasceu, e ele (Léo) já tem seis anos.

Nesse trecho percebemos uma mãe que controlava as decisões familiares, um pai que se subordinava a essas decisões para evitar conflitos e uma criança que não tinha espaço para se desenvolver subjetivamente e construir seus próprios critérios a partir da vivência de novas experiências, já que "o novo" era subjetivado como "arriscado" ou "perigoso" por essa mãe.

O próximo trecho, retirado ainda da primeira sessão de Léo, mostra sua falta de recursos subjetivos para definir suas próprias preferências, gostos, vontades e limites, sustentando a hipótese de que sua dificuldade de se posicionar estava relacionada à forma como sua família se organizava, com a mãe sendo o centro das decisões, detentora de todo controle.

Psicoterapeuta: E seus amigos? Você tem muitos?

Léo: Sim.

Psicoterapeuta: Quais os nomes deles?

(Léo citou alguns nomes).

Psicoterapeuta: Quais você gosta mais?

Léo: Todos.

Psicoterapeuta: Não tem nenhum desses que não seja legal?

Léo: Só o Thiago, porque ele faz bumbunzinho...

Psicoterapeuta: Como é bumbunzinho?

(Léo se levanta e faz rapidamente: balança o bumbum como se fosse encostar em alguém).
Psicoterapeuta: Você não gosta?

Léo: Não.

Psicoterapeuta: E você fala para ele parar?

Léo: Não...

Psicoterapeuta: Por quê?

Léo: Porque eu não sou adulto para mandar...

Psicoterapeuta: Mas isso não é mandar... É você dizer que não gosta, para ele saber que isso te incomoda. Se você não falar, ele não vai saber e não vai parar. Ele pode até achar que você gosta... Você pode dizer: Thiago, não gosto dessa brincadeira... vamos brincar de outra coisa?

Percebemos a congruência de diversas informações que corroboram com os indicadores construídos acerca dos processos subjetivos de Léo: ele chorava muito; sempre se desculpava; o adulto era quem dizia o que fazer; se ele fazia alguma coisa que não estava autorizada ou não estava coordenada por um adulto, ele se sentia incapaz, incompetente e errado. Esses indicadores sustentam a hipótese acima mencionada, sobre o excesso de controle, por parte da mãe, ser configuradora da subjetividade social da família, não favorecendo que os demais membros familiares se colocassem como sujeito em suas próprias vivências, pois estavam sempre dependendo da orientação ou autorização dessa mãe para que suas ações fossem legitimadas.

A rigidez expressada por Léo, também aparecia na sua falta de imaginação durante as brincadeiras. Léo se mantinha sempre no concreto, no objetivo e no real. No trecho abaixo, assim como em outros momentos, percebemos sua dificuldade de adentrar o mundo da imaginação

Psicoterapeuta: Hummm... O que é isso que você está fazendo? Parece gostoso...

Léo: Um bolo.

Psicoterapeuta: Que delícia! Posso provar?

Léo: Isso não é bolo de verdade, é só massinha.

Psicoterapeuta: Mas a gente pode fingir que é de verdade... Será que esse bolo é gostoso? 
Léo ficou calado.

Psicoterapeuta: Eu estou fazendo rosquinha. Você gosta?

\section{Léo: Gosto.}

Psicoterapeuta: Quer provar?

Léo: Não... não pode comer massinha.

Psicoterapeuta: Mas não é pra provar de verdade, é só fazer de conta. Quer?

Léo: Não, obrigado.

A imaginação é uma expressão clara de liberdade e segurança (Muniz, 2019), pois permite novas construções que transpõem a realidade e se expressa na criatividade que é, também, favorecedora da emergência do indivíduo como sujeito em suas vivências. A fantasia aparece como um momento de liberdade, para sentirmos o mundo de outra forma e podermos criar. Mas quando precisamos controlar tudo o que sentimos e fazemos, a imaginação também fica embotada.

Percebemos que esse contexto familiar era configurado subjetivamente por Léo como um lugar inseguro, onde ele não reconhecia mais o seu espaço e o seu papel. $\mathrm{Na}$ faixa etária de Léo, seis anos, as crianças ainda costumam ficar muito desorientadas e confusas diante de perdas ou morte, procurando aquela pessoa que agora falta. Geralmente, ainda não compreendem com clareza o que aconteceu, por falta de recursos subjetivos para lidar com a ausência e as emoções atreladas a ela.

Nesse ponto da pesquisa, já podemos reconhecer a construção de um modelo teórico, o qual nos dá maior inteligibilidade acerca da subjetividade social familiar e seus desdobramentos nos processos subjetivos da criança.

A partir das hipóteses construídas, as sessões seguintes foram orientadas a mobilizar Léo em produções subjetivas à respeito de si mesmo, seu papel no seio familiar, seu espaço, preferências, escolhas, limites e vontades. Em uma dessas sessões, foi utilizada uma tela e tinta guache como instrumento para que Léo se expressasse espontaneamente. Com base nas rejeições de Léo às brincadeiras que poderiam sujar as mãos ou as roupas, era esperado que a utilização de tinta pudesse ser mobilizadora de sentidos subjetivos de desconforto quanto à se sujar ou sujar o consultório, mas, mesmo assim, foi dado a ele novamente essa oportunidade de vivenciar algo novo.
Psicoterapeuta: Vai querer brincar de que hoje?

Léo não falou nada, mas pegou a tela que estava no chão perto dele.

Psicoterapeuta: Pintura? Legal! Você gosta de pintar?

Léo: Sim. Mas nunca pinto. Só na escola, às vezes. Pegou as tintas e começou a pintar uma pessoa.

Psicoterapeuta: Quem é essa pessoa?

Léo: Um menino de retrato.

Psicoterapeuta: Você o conhece?

Léo: Não. É só um menino de retrato.

O menino começou a ficar muito parecido com ele: cabelo preto de lado e olhos bem grandes. O contorno do rosto era quadrado. Boca reta, sem expressão de sorriso.

Léo: Esse menino é quadrado.

Psicoterapeuta: Então ele é diferente dos outros meninos?

Léo: Sim, é diferente.

Psicoterapeuta: E o que ele gosta de fazer?

Léo: Ele não faz nada, é só um menino de retrato. Não gosta de nada...

Psicoterapeuta: Mas ele é feliz sendo um menino de retrato?

Ficou calado por um tempo.

Léo: Não sei... acho que não.

Psicoterapeuta: Bom, todas as pessoas são diferentes umas das outras. Ninguém é igual. E eu acho isso muito bom! Adoro ser diferente. Todos são especiais da forma que são. Não vejo nenhum problema desse menino ser quadrado.

Ele ouviu em silencio enquanto continuava a pintar e depois disse:

Léo: É, não tem problema ser diferente. Acho que esse menino é eu... 


\section{DE DESENVOLVIMENTO SUBJETIVO INFANTIL}

Psicoterapeuta: Ele é muito bonito. Sua pintura está linda. Você é um artista?

Léo: É, sou artista. Eu pinto bem, não é?

Psicoterapeuta: Sim, você pinta muito bem.

Ele parou de pintar por um tempo e ficou admirando o desenho em silêncio. Depois, pegou a tinta preta e começou a cobrir o desenho todo, virando tudo uma mancha preta.

Léo: Não, esse menino não é mais eu. Esse é só um menino de retrato.

Psicoterapeuta: Tudo bem. E você, como é?

Léo: Já terminei... Posso lavar minha mão?

A pintura de Léo expressava subjetivamente a forma como ele se percebia: um menino "quadrado", apático e diferente dos outros garotos. Ao dizer que aquele menino era ele, estava revelando a forma como se via. Porém, ele não gostava de ser diferente, ficando desconfortável consigo mesmo muitas vezes. À medida que novos sentidos subjetivos emergiam, tanto dentro do espaço psicoterapêutico, quanto em outros contextos sociais, novas configurações subjetivas à respeito de si foram formadas e, ao reconhecer que ser diferente é bom, ao invés de um problema, Léo apagava com tinta preta aquele menino apático, desenhado de forma quadrada, como se estivesse, também, apagando aquela interpretação de si e possibilitando a emergência de novos sentidos subjetivos sobre quem ele era.

Outras expressões de Léo, destacadas mais adiante, corroboraram com a interpretação de um possível desenvolvimento subjetivo a partir da mobilização e constituição de novas configurações subjetivas. No espaço psicoterapêutico, por exemplo, com o passar das sessões, Léo já entrava na sala de atendimento dizendo exatamente com o que ele gostaria de brincar:

Léo: A gente vai brincar hoje, né?

Psicoterapeuta: Você quer brincar?

Léo: Quero, claro!

Psicoterapeuta: Então de quê?

Léo: De slime!
Esse trecho chama a atenção por dois aspectos: o primeiro, o fato de Léo falar confiante que queria brincar e escolher a brincadeira com tanta segurança. O segundo, ele escolher o slime, pois, em várias sessões anteriores, ele abria o pote, encostava o dedo e fechava. Algumas vezes tentava pegar, mas quando percebia que grudava, ou quando caia perto de sua roupa, se assustava, pulava para trás e pedia ajuda para tirar de sua mão. Expressava medo em sujar: "Nossa, quase grudou na minha roupa... se grudar vai manchar e não sai nunca mais!".

Porém, esse encontro no qual optou por essa brincadeira, ele não só quis brincar com toda a slime em suas mãos, como também propôs uma guerra de slime. Ele pegou um pedaço e jogou na psicoterapeuta que, então, fez o mesmo, começando uma guerra. Léo estava muito animado, rindo alto, gritando sem parar. Parecia estar vivenciando um momento de muita liberdade e prazer por subverter as regras que, até então, o aprisionavam.

Durante a brincadeira ele disse: “tia, isso está muito divertido, não é?”, essas verbalizações de suas emoções eram sempre uma novidade e iam, processualmente, revelando um processo de desenvolvimento subjetivo que se configurava a partir da emergência dos novos sentidos subjetivos de segurança, coragem e criatividade expressados na nova forma como Léo se relacionava dentro e fora de casa.

Algumas outras mudanças foram se tornando frequentes e aparentes nas ações e expressões de Léo como, por exemplo, quando passou a assumir o controle durante os jogos e as brincadeiras nos atendimentos, quando começou a levar brinquedos da sua casa para brincar no consultório, quando se elogiava (dizia ser um bom amigo, um bom jogador, esperto, rápido, artista, bom pintor), elogiava suas obras artísticas e, principalmente, quando começou a expressar mudanças na sua relação com os pais.

$\mathrm{Na}$ última conversa realizada com os pais, foi possível sustentar a hipótese de que Léo estava passando por um processo de desenvolvimento subjetivo que se expressava em mudanças no campo vivido e passavam a configurar seu modo de ser:

Tatiana: Percebo que ele está muito mais sociável. A gente chega em um restaurante, quando tem parquinho, ele vai brincar. Se tem alguma criança monopolizando o brinquedo ele vai lá sozinho e fala com o pai da criança, explica que ela está brincando há muito tempo e que agora deve ser a vez dele, como ele fez quando fomos ao Mc Donald's. Achei isso muito bom. Ele jamais faria isso 
uns meses atrás. E eu só fico de longe olhando, supervisionando, mas não interfiro mais. Deixei ele ir sozinho e resolver. (...) Léo está mais seguro e confiante. Quando está tomando banho ele não quer mais ajuda, já fala que quer tomar banho sozinho. Ele quer pedir o lanche sozinho agora na lanchonete. Me pediu uma carteira também. Comprei a carteira pra ele e, de vez em quando, coloco um dinheiro lá dentro, aí ele compra umas besteiras lá na lanchonete da escola.

O relato de Tatiana nos revela muitas mudanças nas ações e relações de Léo nos mais variados contextos sociais, como escola, restaurante, parquinho e sua própria casa. Isso nos leva a pensar que não eram pontuais ou momentâneas, mas características de novas configurações subjetivas de desenvolvimento que se definem como "mudanças subjetivas que ganham certa estabilidade, originando outras mudanças, gerando novos níveis qualitativos de organização subjetiva" (Rossato, 2009, p. 182, 183).

É importante destacar, também, as mudanças nas ações de Tatiana quanto a dar mais espaço para Léo se desenvolver. Quando ela passa a não interferir em alguns momentos, por perceber que Léo conseguia sozinho se defender, se expressar e resolver suas dificuldades, nos revela uma nova configuração subjetiva de sua maternidade. Essa construção ratifica o nosso modelo teórico quanto à subjetividade social da família ter desdobramentos nos processos subjetivos da criança.

Tatiana: Ah, uma coisa que percebi também, é que eu subestimava demais a capacidade do Léo. Reconheço mesmo isso. Nas atividades da escola eu sempre lia pra ele e explicava tudo. Um dia falei pra ele esperar enquanto eu fazia uma coisa na cozinha e, quando eu voltei, ele já tinha lido, entendido e feito toda a questão! Levei um susto! Nunca imaginei que ele já entenderia sozinho e ainda criaria a frase.

Isso me vez acordar e ver que tenho que dar mais espaço para ele. Preciso deixar ele se desenvolver mais.

Eu o enxergava pequeno, indefeso... e talvez não seja essa a realidade.

Psicoterapeuta: Talvez essa sua percepção dele indefeso, pequeno... se expressasse em outros contextos também, como na via social, e não apenas em relação à aprendizagem.

Tatiana: Ah, sim, isso é verdade. Ele só vai aprender se eu der mais espaço. Preciso expandir essa percepção para outras áreas da vida dele.
Interpretamos a partir desse e outros relatos, que Tatiana estava sendo mobilizada em suas produções subjetivas ao longo do processo psicoterapêutico de seu filho, nos mostrando que a relação dialógica estabelecida pela família com a psicoterapia, possibilita a emergência de configurações subjetivas de desenvolvimento a todos os envolvidos. O espaço psicoterapêutico é promotor de tensionamentos que levam ao desenvolvimento subjetivo do sujeitos. Segundos Rossato e Assunção (2019, p. 59), "os tensionamentos possibilitam os novos caminhos que podem se abrir a partir do mesmo. O tensionamento é um convite a refletir e desafiar o que está posto, não para romper indiscriminadamente, mas para produzir compreensão dos processos".

Todo espaço relacional pode ser mobilizador de transformações, pois as pessoas ali engajadas estão presentes com suas histórias, trajetórias e experiências ricas de símbolos e emoções, implicando em novas vivências de "continuidade e descontinuidade, estabilidade e instabilidade que podem resultar em uma re(construção) ao longo de sua vida" (Rossato e Assunção, 2019, p. 53).

O trecho a seguir convergiu com nossa hipótese a respeito do desenvolvido subjetivo de Léo:

Tatiana: Percebi também que, nesses últimos meses, Léo tem ficado um pouco mais desafiador. Não que ele chegue a me desrespeitar, mas tem questionado mais, me enfrentado mais com as opiniões dele, quando concorda ou não concorda.

Os pais de Léo estavam acostumados com uma criança calada, insegura, que acatava todas as ideias e direções apontadas por eles. Agora, Léo se tornava sujeito em sua própria história, expressando suas vontades, desejos, desagrados, opiniões e preferências. Quando Tatiana disse que Léo estava ficando desafiador, ela estava começando a conhecer o Léo sujeito, ativo e protagonista de sua história. Como escreveram Muniz e Mitjáns Martínez (2019, p. 34), "a categoria sujeito aponta para a possibilidade do indivíduo delimitar um espaço próprio de subjetivação perante as atividades e exigências do espaço social em que se desenvolve, tencionando de alguma forma o estabelecido". Constituir-se sujeito requer um processo de desenvolvimento subjetivo que direcione o indivíduo a novos caminhos que, muitas vezes, confrontam a subjetividade social imposta.

\section{Considerações Finais}

Compreender os processos subjetivos envolvidos no espaço psicoterapêutico, favorecedores de desenvolvimen- 


\section{DE DESENVOLVIMENTO SUBJETIVO INFANTIL}

to subjetivo na criança, exige esforço e muita criatividade para dar visibilidade a esses processos que são complexos, dinâmicos, processuais e singulares.

Nessa perspectiva o pesquisador assume a responsabilidade pelos direcionamentos que conduzirão o processo investigativo, por meio de toda construção da informação elaborada por ele ao longo do caminho percorrido pela pesquisa. Para realização do estudo de caso, o pesquisador constrói formas de diálogo que mobilizam o participante a se expressar de modo autêntico, entretanto, quando se refere à psicoterapia infantil, essa mobilização diz respeito tanto à criança em psicoterapia quanto à sua família.

As pesquisas no campo da psicoterapia são essenciais para elaboração de modelos teóricos que levem à compreensão dos diversos e imprevisíveis fenômenos subjetivos, organizados em configurações subjetivas e que articulam a subjetividade social e a individual. Ao fazer pesquisa em psicoterapia, pode-se evidenciar o valor da teoria como uma ferramenta que norteia a compreensão dos fenômenos humanos e possibilita novas representações sobre os mesmos, pois é nesse contexto que as teorias avançam.

A presente pesquisa trouxe contribuições e maior clareza para compreender os processos subjetivos infantis que são perpassados pela subjetividade social da família na qual essas crianças estão inseridas. Além disso, ficou evidenciada a importância do engajamento familiar no processo psicoterapêutico infantil, quando os pais estão abertos às possíveis mobilizações subjetivas desse processo, pois, quando não se permitem vivenciar essa experiência, muitas vezes não autorizam a criança viver, de forma mais livre, esse caminho, o que implica maior dificuldade da criança se engajar e subjetivar a psicoterapia.

A partir do modelo teórico construído, entendemos que a subjetividade social familiar tem seus desdobramentos nos processos subjetivos da criança e, pela forma como está configurada, pode favorecer ou não a emergência dessa criança como sujeito em suas vivências e alcançar momentos de desenvolvimento subjetivo.

A partir da abordagem teórica da subjetividade, foi possível compreender os processos subjetivamente configurados da psicoterapia infantil e destacar a singularidade do processo de desenvolvimento, fugindo da dicotomização entre o normal e o patológico. Dessa forma, o desenvolvimento subjetivo, como processo singular e subjetivamente configurado, não tem seus desdobramentos como resultados de algo específico, externo ou antecedente. Entender o desenvolvimento subjetivo como configuração subjetiva complexa, nos permite com- preender esse processo humano em sua multiplicidade, sabendo que integra sentidos subjetivos de diversas áreas da vida da pessoa.

A psicoterapia infantil é um espaço de constantes produções subjetivas que se expressam em rupturas, desconstruções, reconstruções, inovações e mudanças das mais diversas, em um movimento contínuo de sentidos subjetivos que emergem na própria experiência vivida nesse espaço dialógico, gerando vivências inéditas que enriquecem a criança e seus familiares envolvidos, com novos recursos subjetivos, por meio de novos alicerces simbólico-emocionais, possibilitando, assim, outros momentos de desenvolvimento subjetivo.

\section{Referências}

González Rey, F. L. (2005). Pesquisa qualitativa e subjetividade: os processos de construção da informação. 2. ed. Tradução de M. A. Ferrada Silva. São Paulo: Cengage Learning.

González Rey, F. L. (2007). Psicoterapia, Subjetividade e Pós-Modernidade: uma aproximação histórico-cultural. Thomson Learning.

González Rey, F. L. (2015). Saúde, cultura e subjetividade: uma referência interdisciplinar. Brasília: UniCEUB.

González Rey, F. L., Goulart, D. M. \& Bezerra, M. S. (2016). Ação profissional e subjetividade: para além do conceito de intervenção profissional na Psicologia. Porto Alegre, v. 39, n. esp. (supl.), s54-s65.

González Rey, F. L. \& Mitjáns Martínez, A. (2017a). Subjetividade: teoria, epistemologia e método. Campinas: Alínea.

González Rey, F. L. \& Mitjáns Martínez, A. (2017b). El desarrollo de la subjetividad: una alternativa frente a las teorías del desarrollo psíquico. Departament de Psicologia, Universitat de Girona. Disponível em: $<$ http://psicologia.udg.edu/PTCEDH/Presentacion.asp>. Acessado em: 3 de junho 2019.

Madeira-Coelho, C. M. (2020). Infância e subjetividade na complexidade de processos de desenvolvimento. In: Mítjans Martínez, A., Tacca, M. C. V. R \& Puentes, R. V. Teoria da Subjetividade: discussões teóricas, metodológicas na prática profissional. Campinas, SP: Alínea

Mitjáns Martínez, A. \& González Rey, F. (2017). Psicologia, educação e aprendizagem escolar: avançando na leitura cultural-histórica. São Paulo: Cortez.

Mitjáns Martínez, A. (2020). Subjetividade social - desafios de um conceito. In: Mítjans Martínez, A., Tacca, M. C. V. R \& Puentes, R. V. Teoria da Subjetividade: discussões teóricas, metodológicas na prática profissional. Campinas, SP: Alínea.

Mori, V. D. \& Goulart, D. M. (2019). Subject and subjectivity within psychotherapy: a case study. In: González Rey, F., Mitjáns Martínez, A. \& Goulart, D. M. (Eds.). Subjectivity within cultural-historical approach: theory, methodology and research. Singapore: Springer.

Mori, V. D. (2020). A prática e a pesquisa com base na Teoria da Subjetividade: a psicoterapia como cenário. In: Mítjans Martínez, A., Tacca, M. C. V. R \& Puentes, R. V. Teoria da Subjetividade: discussões teóricas, metodológicas na prática profissional. Campinas, SP: Alínea.

Muniz, L. S. \& Mítjáns Martínez, A. (2019). Aprendizagem criativa da leitura e da escrita e desenvolvimento. Curitiba: Appris.

Neubern, M. S. (2012). Ensaio sobre a cegueira de Édipo: sobre psicoterapia, política e conhecimento. In Holanda, A. F. et al. O campo das psicoterapias: reflexões atuais (pp.13-45). Curitiba: Juruá.

Oliveira, A. M. C. (2017). Desenvolvimento Subjetivo e Educação: avançando na compreensão da criança que se desenvolve em sala de aula. Dissertação de mestrado. Universidade de Brasília (UnB).

Rossato, M. (2009). O movimento da subjetividade no processo de superação das dificuldades de aprendizagem escolar. Tese de doutorado. Universidade de Brasília (UnB). 
Rossato, M. \& Assunção, R. (2019). O desenvolvimento subjetivo no processo da formação docente. In. Mitjáns Martínez, A., Anache, A. A., Lustosa, A. V. M. F., Fuchijima, B. D., Coelho, C. M. M... Cordeiro, V. O. M. (2019). Formação de educadores e psicólogos - contribuições e desafios da subjetividade na perspectiva cultural-histórica. Curitiba: Appris.
Vygotsky, L. S. (2009). Imaginação e criação na infância. São Paulo: Ática. Winnicott, D. W. (1975). O brincar e a realidade. Rio de Janeiro: Imago.

Winnicott, D. W. (1982). A criança e o seu mundo. 6a ed. Rio de Janeiro: LTC.

Submetido em: 4-3-2021

Aceito em: 11-3-2021 